\title{
Origins of Disparities in Cardiovascular Disease: Birth Weight, Body Mass Index, and Young Adult Systolic Blood Pressure in the National Longitudinal Study of Adolescent Health
}

\author{
Liana J. Richardson, PhD, \\ University of North Carolina at Chapel Hill, Department of Sociology; Carolina Population Center \\ Jon M. Hussey, PhD, and \\ University of North Carolina at Chapel Hill, Gillings School of Global Public Health, Department of \\ Maternal and Child Health; Carolina Population Center
}

Kelly L. Strutz, MPH

University of North Carolina at Chapel Hill, Gillings School of Global Public Health, Department of Maternal and Child Health; Carolina Population Center

\begin{abstract}
PURPOSE-We evaluated the contributions of birth weight and current body mass index (BMI) to racial/ethnic disparities in systolic blood pressure (SBP) in the U.S.

METHODS-Participants were 10,046 young adults (ages 24 - 32) in the National Longitudinal Study of Adolescent Health (Add Health). SBP, BMI, and other contemporaneous factors were assessed at Wave IV (2007-2008); birth weight and other early life factors were reported at Wave I (1994-1995). Data were analyzed using sex- and race-stratified multivariable regression models.

RESULTS-Racial/ethnic disparities in SBP were limited to Black and White females. The Black-White female disparity in SBP was $3.36 \mathrm{mmHg}$ and was partially explained by current BMI but not birth weight. Associations between birth weight and SBP were limited to males, in whom we found a decrease of $1.05 \mathrm{mmHg}$ in SBP per $1 \mathrm{~kg}$ increase in birth weight (95\% CI: -1.90 , -0.20 ). This inverse relationship strengthened after adjusting for BMI and other factors, and was strongest among Black and White males. A significant association between BMI and SBP was found in all racial/ethnic and sex subgroups.
\end{abstract}

CONCLUSION-In this U.S. national cohort, birth weight is negatively associated with SBP among Black and White young adult males.

\section{MeSH KEYWORDS}

birth weight; blood pressure; body mass index; health status disparities; hypertension

As the leading cause of cardiovascular disease (CVD), hypertension is a major contributor to morbidity and premature mortality in the United States (1-3). Although efforts to understand the causes of hypertension have largely focused on proximal risks (4-7), interest in the

(C) 2011 Elsevier Inc. All rights reserved.

Correspondence to: Liana J. Richardson.

Publisher's Disclaimer: This is a PDF file of an unedited manuscript that has been accepted for publication. As a service to our customers we are providing this early version of the manuscript. The manuscript will undergo copyediting, typesetting, and review of the resulting proof before it is published in its final citable form. Please note that during the production process errors may be discovered which could affect the content, and all legal disclaimers that apply to the journal pertain. 
contribution of early life factors, especially birth weight, has grown (8-12). Much of this interest can be traced to the fetal origins hypothesis, which suggests that fetal undernutrition, for which low birth weight is a marker, may permanently program the body in ways that ultimately increase adult CVD risk (13-16).

Few studies of the fetal origins hypothesis using U.S. samples have been published. In addition, one important implication of the fetal origins hypothesis - that racial/ethnic disparities in birth weight may contribute to disparities in CVD-remains under-investigated (17). This gap is especially obvious in the U.S., where rates of both low birth weight and hypertension are significantly higher among Blacks than among Whites, Latinos, and Asians (18-23), and where our understanding of the determinants of these disparities remains incomplete.

We evaluated the fetal origins hypothesis in a large, diverse, and nationally representative U.S. sample, and extended our analysis beyond the Black/White comparisons of other U.S. studies (24) by including Mexican-Origin Latinos and Asian/Pacific Islanders. Our analysis also evaluated the impact of current body mass index (BMI), which appears to play an important but etiologically uncertain role in the birth weight-blood pressure relationship ( 8 , $25,26)$. Finally, we stratified all models by sex, given evidence that the strength and shape of the association between birth weight and SBP differs between females and males (27). In all analyses, we focused on SBP because it is known to be a more clinically significant and reliably measured risk factor for CVD than diastolic blood pressure (DBP) $(8,28)$.

\section{METHODS}

\section{Study population}

This study used data from Waves I and IV of the National Longitudinal Study of Adolescent Health (Add Health), a study of a nationally representative sample of U.S. adolescents in grades 7 through 12 during the 1994-95 school year followed into adulthood.

Approximately 90,000 adolescents completed an in-school questionnaire when the study began. From April to December of 1995 (Wave I), in-home interviews with 20,745 of those adolescents were completed (79\% response rate). At Wave I, a parent also completed an interviewer-assisted questionnaire. At Wave IV (2007-2008), trained interviewers completed follow-up in-home interviews and collected cardiovascular and anthropometric measures from 15,701 of the Wave I respondents, now ages 24-32 years (80\% response rate). Written parental/guardian consent and adolescent assent were obtained prior to the Wave I interview. At Wave IV, written consent was obtained from all respondents. A complete description of the Add Health study design is available elsewhere (29).

We restricted the analysis sample to non-Hispanic Whites, non-Hispanic Blacks, MexicanOrigin Latinos, and Asian/Pacific Islanders. Respondents in racial groups and Latino subgroups with insufficient numbers for analysis $(\mathrm{n}=1,920)$ or who did not report their race/ ethnicity ( $n=49$ ) were excluded. We then excluded respondents sequentially if they met or were missing values for our remaining exclusion criteria, which were based on empirical evidence of their association with birth weight, BMI, and/or SBP-i.e., if they were a product of a multifetal pregnancy $(n=1,485)$, were obese and taking oral contraceptives $(n=530)(3)$, were pregnant $(n=371)$, refused blood pressure measurement $(n=288)$, or had their blood pressure measured with an undersized cuff $(n=111)$. A total of 10,046 respondents (5,091 males and 4,955 females) were retained in our analysis sample.

\section{Measures}

Respondent's SBP was constructed from the average of the second and third of three serial blood pressure measurements in millimeters of mercury $(\mathrm{mmHg})$ on the day of the Wave IV 
interview. The measurements were obtained at 30-second intervals from a resting, seated position using a Microlife oscillometric blood pressure monitor (MicroLife USA, Inc.; Dunedin, FL) (30), and have been shown to be accurate and reliable (31). To adjust for hypertension treatment effects, we applied a previously validated strategy of adding 10 $\mathrm{mmHg}$ to the SBPs of respondents identified as antihypertensive medication users $(\mathrm{n}=340)$ $(32,33)$.

Respondent's birth weight was determined from parent's (typically mother's) report in the Wave I parent interview and converted from pounds and ounces to grams, making it consistent with clinical measurements of birth weight (34). Multiple validation studies have concluded that maternal recall of birth weight is sufficiently accurate to support epidemiological investigations (35-39). To reduce deductive disclosure risk, which is a particular concern for Add Health given its clustered research design and data on highly sensitive topics, birth weights were top- and bottom-coded at $\geq 12$ pounds and $<4$ pounds, respectively (impacting $<5 \%$ of respondents).

Respondent's race/ethnicity was determined from his/her Wave I answers to the questions: "What is your race?", "Are you Hispanic or Latino(a)?", and "What is your Hispanic/Latino background?", and classified as Non-Hispanic White, Mexican-Origin Latino, Non-Hispanic Black, and Asian/Pacific Islander.

Respondent's current BMI was calculated from measurements of his/her height and weight on the day of the Wave IV interview using the formula: BMI = [weight in kilograms/(height in meters $)^{2}$ ]. Height was assessed to the nearest $0.5 \mathrm{~cm}$ with a steel tape measure, while weight was assessed to the nearest $0.1 \mathrm{~kg}$ using a digital bathroom scale (Jarden Corporation; Rye, NY) (30).

Respondent's age, education, smoking behavior, alcohol consumption, and physical activity at Wave IV, as well as his/her nativity, mother's education, and mother's smoking behavior at Wave I, were treated as potential confounders. (See Table 1 for values and categories of these variables).

\section{Statistical analysis}

Univariate and bivariate analyses were performed to examine overall, sex-specific, and racespecific distributions of key variables. We used linear regression to assess the crude associations between race/ethnicity and SBP, and between birth weight and SBP. Multiple linear regression analysis was used to evaluate whether adjusting for current BMI altered the association between birth weight and SBP, to determine whether adjusting for birth weight and current BMI attenuated the association between race/ethnicity and SBP, and to adjust for potential confounders. We also estimated those models with an interaction term for birth weight and current BMI included. We stratified the sample by race/ethnicity and reestimated the fully adjusted models separately to determine the extent of racial/ethnic differences in the effect of birth weight (and current BMI) on SBP. We then re-estimated all previously described models, stratified by sex, to highlight both sex-specific and race*sexspecific effects.

With the exception of race/ethnicity, age, sex, and SBP, missing values on covariates were imputed using multiple imputation. Our results and conclusions were not sensitive to the use of imputed versus original data, or to the retention versus exclusion of individuals receiving antihypertensive therapy. Thus, we report findings based on imputed data including medication users here. All analyses were conducted in Stata Version 11 (StataCorp, College Station, TX) and accounted for the Add Health complex survey design. 


\section{RESULTS}

Descriptive statistics for the study population are shown in Table 1. Average birth weight, $\mathrm{SBP}, \mathrm{BMI}$, and age were $3.36 \mathrm{~kg}(\mathrm{SE}=0.01), 125.6 \mathrm{mmHg}(\mathrm{SE}=0.22), 28.4 \mathrm{~kg} / \mathrm{m}^{2}(\mathrm{SE}=$ 0.12 ) and 28.8 years old $(\mathrm{SE}=0.12)$, respectively. Non-Hispanic Black, Mexican-Origin, and Asian/Pacific Islander participants accounted for approximately $16 \%, 8 \%$, and $3 \%$ of the study population, respectively. The majority of participants (89\%) were U.S.-born to U.S.-born parents. About one-third of respondents indicated that their biological mother smoked and 20\% reported that their mother obtained a GED or did not complete high school. About one quarter of respondents reported being daily smokers, while less than 3\% were heavy drinkers. On average, respondents reported 6.5 bouts of physical activity per week $(\mathrm{SE}=0.09)$ and $12 \%$ indicated that they obtained a GED or did not complete high school. Roughly $3.5 \%$ of participants were antihypertensive medication users. (See supplemental table for information about the race/ethnicity and birth weight distribution of medication users).

The distributions of race/ethnicity, nativity, age, antihypertensive medication use, mother's smoking behavior, and mother's education were similar for females and males. In addition, average BMI among females $\left(\mathrm{M}=28.1 \mathrm{~kg} / \mathrm{m}^{2}, \mathrm{SE}=0.19\right)$ and males $\left(\mathrm{M}=28.7 \mathrm{~kg} / \mathrm{m}^{2}, \mathrm{SE}=\right.$ 0.13 ) was similar and met the consensus criterion for overweight. However, sex differences were apparent for birth weight, SBP, and other contemporaneous conditions. Mean birth weight among females $(\mathrm{M}=3.30, \mathrm{SE}=0.02)$ was lower than that of males $(\mathrm{M}=3.41, \mathrm{SE}=$ 0.01). Mean SBP for females hit the $120 \mathrm{mmHg}$ threshold for prehypertension (40), while mean $\mathrm{SBP}$ for males exceeded this value $(\mathrm{M}=130.2 \mathrm{mmHg}, \mathrm{SE}=0.29)$. Males also were more likely than females to report being daily smokers, heavy drinkers, having a high school diploma or less, and engaging in physical activity.

Racial/ethnic and sex disparities in birth weight, BMI, and SBP are described in Table 2. Among females, Blacks were the only racial/ethnic-sex group with a mean SBP that was significantly higher than Whites (by $3.3 \mathrm{mmHg}$ ). This suggests that Black females were largely responsible for driving the overall mean SBP for females upward. Compared to White females, Black and Mexican-Origin females had significantly higher average BMIs (by $3.3 \mathrm{~kg} / \mathrm{m}^{2}$ and $2.0 \mathrm{~kg} / \mathrm{m}^{2}$, respectively), while Asian/Pacific Islanders had a significantly lower average BMI (by $2.8 \mathrm{~kg} / \mathrm{m}^{2}$ ). The latter group also had a significantly lower average birth weight than White females (by $0.18 \mathrm{~kg}$ ). No racial/ethnic disparities in SBP were apparent among males. However, males in all non-White racial/ethnic groups were significantly lighter than Whites at birth (by 0.11 to $0.27 \mathrm{~kg}$ ), and Mexican-Origin Latinos had a significantly higher mean BMI than White males (by $1.6 \mathrm{~kg} / \mathrm{m}^{2}$ ). Birth weight and BMI were correlated only among Black females and White males $(r=0.14, p<.01$ and $r=$ $0.05, p<.05$, respectively; data not shown).

Table 3 summarizes the simple and adjusted associations between birth weight and SBP, as well as the role of BMI, stratified by sex. In the simple, unadjusted model (Model 1), a $1 \mathrm{~kg}$ increase in birth weight was associated with a statistically significant decrease in SBP $(-1.05 \mathrm{mmHg} / \mathrm{kg} ; 95 \% \mathrm{CI}:-1.90,-0.20)$ among males, but not among females. No interaction between birth weight and BMI was detected ( $p>0.05$; results not shown). Thus, in Model 2, we adjusted for BMI and found that the inverse relationship between birth weight and SBP among males strengthened $(-1.37 \mathrm{mmHg} / \mathrm{kg}$; 95\% CI: $-2.20,-0.54)$. Adding controls for early life characteristics in Model 3 and contemporaneous conditions in Model 4 further strengthened the relationship. Across Models 2 through 4 and for both males and females, BMI had a strong positive and statistically significant relationship with $\mathrm{SBP}$ relative to other characteristics $\left(0.6 \mathrm{mmHg}\right.$ per $1 \mathrm{~kg} / \mathrm{m}^{2}$ increase in BMI). 
Table 4 presents the results of sex-specific regression models of the relationship between race/ethnicity and SBP. In Model 1, we found that Black females had SBPs that were significantly higher (on average) than those of White females (by $3.36 \mathrm{mmHg}$ ) and Asian/ Pacific Islander females (by $5.88 \mathrm{mmHg}$ ). Females in other racial/ethnic groups and males in all non-White racial/ethnic groups did not have SBPs that were significantly different from Whites. Adding birth weight to the model (Model 2) did not impact the results for males or females substantially. However, when BMI was introduced (Model 3), the magnitude of the regression estimate for Black females was attenuated by $2.18 \mathrm{mmHg}$ and was no longer statistically significant. In contrast, the estimate for Mexican-Origin females increased in magnitude and became significant. Specifically, they had SBPs that were $2.18 \mathrm{mmHg}$ lower on average (95\% CI: $-3.69,-0.67)$ than those of White females when birth weight and BMI were held constant. This inverse relationship remained, albeit without statistical significance, when respondent's nativity and mother's educational attainment and smoking status were held constant in Model 4 and when we further adjusted for contemporaneous conditions in Model 5.

Because these pooled sample results have the potential to mask important racial/ethnic differences in covariate effects, we re-estimated the fully adjusted model (Table 4, Model 5) separately for each racial/ethnic group. As Table 5 shows, the statistically significant negative effect of birth weight on SBP we found for males overall did not hold in all racial/ ethnic groups: the birth weight effect on SBP was significant only among Black $(-2.43$ $\mathrm{mmHg} / \mathrm{kg}$; 95\% CI: $-4.21,-0.65)$ and White $(-1.45 \mathrm{mmHg} / \mathrm{kg} ; 95 \% \mathrm{CI}:-2.47,-0.42)$ males. Table 5 also reveals differences in the magnitude of the effect of BMI on SBP across racial/ethnic groups, with the strongest associations among Asian/Pacific Islanders. When we evaluated effect modification by race/ethnicity using interaction terms (results not shown), we found that the association between BMI and SBP was significantly stronger for Asian/Pacific Islander males $\left(1.01 \mathrm{mmHg} / \mathrm{kg} / \mathrm{m}^{2} ; 95 \%\right.$ CI: $\left.0.62,1.39\right)$ than for White males (0.54 mmHg/kg/m²; 95\% CI: $0.43,0.65)$.

\section{DISCUSSION}

Three major aims motivated this study. First, we sought to evaluate the fetal origins hypothesis by estimating simple and adjusted associations between birth weight and SBP overall and by sex. We found a small but statistically significant unadjusted association between birth weight and SBP in males, similar in magnitude to prior estimates $(12,27)$. We did not find this association in females, however. Together, these findings are consistent with the thesis that male fetuses may be more vulnerable to fetal programming of CVD than females (41), but not with recent meta-analyses that either found no evidence of sex differences (42) or a stronger association among females (27).

Another aim of our study was to contribute to the debate about the role of current body size in the relationship between birth weight and SBP. We found that adjusting for current BMI strengthened the association between birth weight and SBP among males. This amplification is a common finding $(27,43)$ for which three possible explanations have been offered: 1 ) BMI suppresses the true relationship between birth weight and SBP; 2) net of current BMI, birth weight measures the impact of post-natal growth on SBP; and 3) controlling for BMI confounds the relationship between birth weight and SBP if it functions as a mediator and shares unmeasured causes with SBP (44). Alternatively, some researchers have suggested that BMI modifies the impact of birth weight on SBP, due to evidence that risk is concentrated in those who were small at birth but large as adults (8). However, in the pooled sample and across all 14 race/ethnicity, sex, and race/ethnicity-sex subpopulations, we found little support for this assertion. 
Third, we examined the contribution of birth weight to disparities in young adult SBP. We found that mean SBP among Blacks was significantly higher than among Whites and Asian/ Pacific Islanders and, as found in the CARDIA (45) and NHANES samples (31), these disparities were largely limited to females. If racial/ethnic differentials in birth weight explain disparities in SBP, then controlling for birth weight should have attenuated or completely eliminated these gaps. Yet we did not find this result.

Like other recent studies (46), a significant positive association between current BMI and SBP was one of our most consistent findings. BMI also appeared to play a key role in the emergence of disparities in SBP. Adjusting for current BMI reduced the Black-White SBP gap by $64 \%$ in the female sample, and more than doubled the SBP advantage that MexicanOrigin females enjoy over White females. The latter finding is a novel one that merits further investigation.

\section{Strengths and Limitations}

This study focused on the relationship between birth weight and SBP in young adulthood, which is a critical period of the life course during which blood pressure disparities are known to increase (45). It is the first study of the fetal origins of blood pressure to estimate the impact of birth weight on racial/ethnic disparities in SBP including the two fastest growing racial/ethnic groups in the U.S.-i.e., Mexican-Origin Latinos and Asian/Pacific Islanders (47), although our sample size for the latter group was small relative to the other groups. By utilizing a large, diverse, and nationally representative sample, this study has greater generalizability and statistical power than previous U.S. investigations that have relied on much smaller, regional samples $(24,48)$. Furthermore, Add Health's prospective cohort design and exceptional breadth of available measures, including measured SBP and an extensive set of socio-demographic and behavioral measures, afforded us the opportunity to include in our models a more complete set of prospectively measured potential confounders than has typically been included.

An important limitation—shared by most fetal programming studies-pertains to the adequacy of our pre- and post-natal measures. While studies have demonstrated the validity of maternal recall of infant birth weight (35-39), the measurement error associated with this measure relative to medical records may attenuate estimated relationships between birth weight and SBP $(49,50)$. Birth weight also has been considered a poor proxy for the fetal environment $(8,51)$, and our measures of maternal education and maternal smoking were rough proxies, given the time lag between respondent's birth and the Wave I interview. However, we did not have other measures, such as infant gestational age, prenatal diet, or prenatal blood pressure. We also were unable to include information about postnatal growth during early childhood, another factor implicated in the development of adult disease $(8,52$, 53). Nevertheless, our study was justified by previous evidence that birth weight impacts blood pressure independent of postnatal growth $(54,55)$.

\section{Conclusion}

Although we found support for the fetal programming of SBP only among males (especially Black and White males) in this young adult sample, we consider this finding important in light of the emergence of dramatic gender differences in CVD risk during adolescence (56). In addition, our estimated effect size may be conservative if the error associated with maternal recall of infant birth weight attenuated it. It also may be conservative if the relationship between birth weight and SBP increases with age, as some studies have suggested $(27,49,57)$. Similarly, given evidence that racial/ethnic differences in SBP grow with age (45), the small disparities in this young adult cohort may still be important. 
Our results suggest that contemporaneous factors (especially BMI) also are key predictors of, and contributors to racial/ethnic disparities in, young adult SBP. This finding is important given that our study cohort came of age during the obesity epidemic, and is consistent with past studies identifying obesity as a key determinant of racial/ethnic disparities in blood pressure (45). It is also possible, however, that our contemporaneous measures are actually capturing the cumulative impact of life course exposures. Future studies to test this possibility, as well as the pathways linking early life factors and life course exposures to young adult CVD risk, are needed. Such studies, especially when conducted with large, diverse, and nationally representative samples, are important for determining the most appropriate timing and targets for intervention. Although the Add Health Wave IV cohort is younger than those used in many fetal origins studies, chronic disease risk factors that have emerged by early adulthood are highly predictive of future mortality risk (58-61). It is, therefore, an important age group to study and one where intervention may matter most for reducing racial/ethnic disparities in premature mortality due to hypertension.

\section{Supplementary Material}

Refer to Web version on PubMed Central for supplementary material.

\section{Acknowledgments}

This work was supported by the Eunice Kennedy Shriver National Institute of Child Health and Human Development at the National Institutes of Health (grant numbers R01-HD057073, R01-HD058535, and T32HD052468-02). This research uses data from Add Health, a program project directed by Kathleen Mullan Harris and designed by J. Richard Udry, Peter S. Bearman, and Kathleen Mullan Harris at the University of North Carolina at Chapel Hill, and funded by grant P01-HD31921 from the Eunice Kennedy Shriver National Institute of Child Health and Human Development (NICHD), with cooperative funding from 23 other federal agencies and foundations. Special acknowledgment is due Ronald R. Rindfuss and Barbara Entwisle for assistance in the original design. Information on how to obtain the Add Health data files is available on the Add Health website (http://www.cpc.unc.edu/addhealth). No direct support was received from grant P01-HD31921 for this analysis. The authors would like to thank Ping Chen, Quynh Nguyen, and Chirayath Suchindran for their assistance with statistical analysis and/or programming; and Kathryn Rose and Eric Whitsel for their feedback on an earlier version of this work.

\section{ABBREVIATIONS AND ACRONYMS}

$\begin{array}{ll}\text { Add Health } & \text { National Longitudinal Study of Adolescent Health } \\ \text { BMI } & \text { Body Mass Index } \\ \text { CARDIA } & \text { Coronary Artery Risk Development in Young Adults Study } \\ \text { CI } & \text { Confidence Interval } \\ \text { CVD } & \text { Cardiovascular Disease } \\ \text { GED } & \text { General Educational Development Certificate } \\ \text { Hg } & \text { Mercury } \\ \text { M } & \text { mean } \\ \text { NHANES } & \text { National Health and Nutrition Examination Survey } \\ \text { SBP } & \text { Systolic Blood Pressure } \\ \text { SE } & \text { Standard Error } \\ \text { U.S } & \text { United States }\end{array}$




\section{References}

1. Egan BM, Zhao Y, Axon RN. US trends in prevalence, awareness, treatment, and control of hypertension, 1988-2008. JAMA. 2010; 303(20):2043-50. [PubMed: 20501926]

2. Stamler J, Stamler R, Neaton JD. Blood pressure, systolic and diastolic, and cardiovascular risks: United States population data. Arch Intern Med. 1993; 153(5):598-615. [PubMed: 8439223]

3. Lloyd-Jones D, Adams RJ, Brown TM, et al. Heart disease and stroke statistics - 2010 update: a report from the American Heart Association. Circulation. 2010; 121(7):E46-E215. [PubMed: 20019324]

4. Kurian AK, Cardarelli KM. Racial and ethnic differences in cardiovascular disease risk factors: a systematic review. Ethn Dis. 2007; 17(1):143-52. [PubMed: 17274224]

5. Hajjar I, Kotchen JM, Kotchen TA. Hypertension: trends in prevalence, incidence, and control. Annu Rev Public Health. 2006; 27:465-90. [PubMed: 16533126]

6. Thorpe RJ Jr, Brandon DT, LaVeist TA. Social context as an explanation for race disparities in hypertension: findings from the Exploring Health Disparities in Integrated Communities (EHDIC) Study. Soc Sci Med. 2008; 67(10):1604-11. [PubMed: 18701200]

7. Ogden CL, Carroll MD, Curtin LR, et al. Prevalence of overweight and obesity in the United States, 1999-2004. JAMA. 2006; 295(13):1549-55. [PubMed: 16595758]

8. Adair L, Dahly D. Developmental determinants of blood pressure in adults. Annu Rev Nutr. 2005; 25:407-34. [PubMed: 16011473]

9. Huxley RR, Shiell AW, Law CM. The role of size at birth and postnatal catch-up growth in determining systolic blood pressure: a systematic review of the literature. J Hypertens. 2000; 18(7): 815-31. [PubMed: 10930178]

10. Hardy R, Wadsworth MEJ, Langenberg C, et al. Birthweight, childhood growth, and blood pressure at 43 years in a British birth cohort. Int J Epidemiol. 2004; 33(1):121-9. [PubMed: 15075157]

11. Law CM, Deswiet M, Osmond C, et al. Initiation of hypertension in utero and its amplification throughout life. BMJ. 1993; 306(6869):24-7. [PubMed: 8435572]

12. Leon DA, Johansson M, Rasmussen F. Gestational age and growth rate of fetal mass are inversely associated with systolic blood pressure in young adults: an epidemiologic study of 165,136 Swedish men aged 18 years. Am J Epidemiol. 2000; 152(7):597-604. [PubMed: 11032153]

13. Barker DJP, Osmond C. Infant mortality, childhood nutrition, and ischemic heart disease in England and Wales. Lancet. 1986; 327(8489):1077-81. [PubMed: 2871345]

14. Barker DJP. In utero programming of chronic disease. Clin Sci. 1998; 95(2):115-28. [PubMed: 9680492]

15. Barker DJP, Osmond C, Golding J, et al. Growth in utero, blood pressure in childhood and adult life, and mortality from cardiovascular disease. BMJ. 1989; 298(6673):564-7. [PubMed: 2495113]

16. Barker, DJP. Mothers, Babies, and Disease in Later Life. London: BMJ Publishing Group; 1994.

17. Gillum RF. Low birthweight and black-white differences in hypertension. J Natl Med Assoc. 1993; 85(9):657. [PubMed: 8120923]

18. Martin JA, Hamilton BE, Sutton PD, et al. Births: final data for 2006. Natl Vital Stat Rep. 2009; 57(7):1-102.

19. Hoyert DL, Mathews TJ, Menacker F, et al. Annual summary of vital statistics: 2004. Pediatrics. 2006; 117(1):168-83. [PubMed: 16396875]

20. Centers for Disease Control and Prevention (CDC). Racial/ethnic disparities in prevalence, treatment, and control of hypertension - United States, 1999-2002. MMWR Morb Mortal Wkly Rep. 2005; 54(1):7-9.

21. Ong KL, Cheung BMY, Man YB, et al. Prevalence, awareness, treatment, and control of hypertension among United States adults, 1999-2004. Hypertension. 2007; 49(1):69-75. [PubMed: 17159087]

22. Barnes, PM.; Adams, PF.; Powell-Griner, E. Advance Data from Vital and Health Statistics. Hyattsville, MD: National Center for Health Statistics; 2008. Health characteristics of the Asian adult population: United States, 2004-2006. 
23. Ostchega, Y.; Yoon, SS.; Hughes, J., et al. NCHS Data Brief no. 3. Hyattsville, MD: National Center for Health Statistics; 2008. Hypertension awareness, treatment, and control - continued disparities in adults: United States, 2005-2006.

24. Cruickshank JK, Mzayek F, Liu L, et al. Origins of the "black/white" difference in blood pressure: roles of birth weight, postnatal growth, early blood pressure, and adolescent body size: the Bogalusa Heart study. Circulation. 2005; 111(15):1932-7. [PubMed: 15837946]

25. Lucas A, Fewtrell MS, Cole TJ. Education and debate: fetal origins of adult disease: the hypothesis revisited. BMJ. 1999; 319(7204):245-9. [PubMed: 10417093]

26. Tu YK, West R, Ellison GTH, et al. Why evidence for the fetal origins of adult disease might be a statistical artifact: the "reversal paradox" for the relation between birth weight and blood pressure in later life. Am J Epidemiol. 2005; 161(1):27-32. [PubMed: 15615910]

27. Gamborg M, Byberg L, Rasmussen F, et al. Birth weight and systolic blood pressure in adolescence and adulthood: meta-regression analysis of sex- and age-specific results from 20 Nordic studies. Am J Epidemiol. 2007; 166(6):634-45. [PubMed: 17456478]

28. Kannel WB. Prevalence and implications of uncontrolled systolic hypertension. Drugs Aging. 2003; 20(4):277-86. [PubMed: 12641483]

29. Harris, KM.; Halpern, CT.; Whitsel, EA., et al. The National Longitudinal Study of Adolescent Health: Research Design. Chapel Hill, NC: Carolina Population Center, University of North Carolina; 2009. (http://www.cpc.unc.edu/projects/addhealth/design)

30. Entzel, P.; Whitsel, EA.; Richardson, A., et al. Add Health Wave IV Documentation: Cardiovascular and Anthropometric Measures. Chapel Hill, NC: Carolina Population Center, University of North Carolina; 2009.

31. Nguyen QT, Tabor JW, Schuft C, et al. Accuracy and reliability of blood pressure in a nationally representative population-based field study: The National Longitudinal Study of Adolescent Health (Add Health), Wave IV. 50th Ann Conf CVD Epid Prev. 2010:P258.

32. Cui J, Hopper J, Harrap SB. Genes and family environment explain correlations between blood pressure and body mass index. Hypertension. 2002; 40:7-12. [PubMed: 12105130]

33. Tobin MD, Sheehan NA, Scurrah KJ, et al. Adjusting for treatment effects in studies of quantitative traits: antihypertensive therapy and systolic blood pressure. Stat Med. 2005; 24:29112935. [PubMed: 16152135]

34. Nguyen RHN, Wilcox AJ. Terms in reproductive and perinatal epidemiology: 2. perinatal terms. J Epidemiol Community Health. 2005; 59(12):1019-21. [PubMed: 16286486]

35. Adegboye ARA, Heitmann BL. Accuracy and correlates of maternal recall of birthweight and gestational age. BJOG. 2008; 115(7):886-93. [PubMed: 18485168]

36. Oberg S, Ge D, Cnattingius S, et al. Ethnic differences in the association of birth weight and blood pressure: the Georgia Cardiovascular Twin Study. Am J Hypertens. 2007; 20(12):1235-41. [PubMed: 18047911]

37. Tate AR, Dezateux C, Cole TJ, et al. Factors affecting a mother's recall of her baby's birth weight. Int J Epidemiol. 2005; 34(3):688-95. [PubMed: 15737964]

38. Tomeo CA, Rich-Edwards JW, Michels KB, et al. Reproducibility and validity of maternal recall of pregnancy-related events. Epidemiology. 1999; 10(6):774-7. [PubMed: 10535796]

39. Walton KA, Murray LJ, Gallagher AM, et al. Parental recall of birthweight: A good proxy for recorded birthweight? Eur J Epidemiol. 2000; 16(9):793-6. [PubMed: 11297220]

40. Chobanian AV, Bakris GL, Black HR, et al. The seventh report of the Joint National Committee on Prevention, Detection, Evaluation, and Treatment of High Blood Pressure: the JNC 7 report. JAMA. 2003; 289(19):2560-72. [PubMed: 12748199]

41. Godfrey KM, Barker DJP. Fetal nutrition and adult disease. Am J Clin Nutr. 2000; 71(5):1344S52S. [PubMed: 10799412]

42. Lawlor DA, Ebrahim S, Smith GD. Is there a sex difference in the association between birth weight and systolic blood pressure in later life? Findings from a meta-regression analysis. Am J Epidemiol. 2002; 156(12):1100-4. [PubMed: 12480654]

43. Mzayek F, Hassig S, Sherwin R, et al. The association of birth weight with developmental trends in blood pressure from childhood through mid-adulthood - the Bogalusa Heart Study. Am J Epidemiol. 2007; 166(4):413-20. [PubMed: 17525085] 
44. Dahly DL, Adair LS, Bollen KA. A structural equation model of the developmental origins of blood pressure. Int J Epidemiol. 2009; 38(2):538-48. [PubMed: 19039006]

45. Liu K, Ruth KJ, Flack JM, et al. Blood pressure in young black and whites: relevance of obesity and lifestyle factors in determining differences - The CARDIA study. Circulation. 1996; 93(1):606. [PubMed: 8616942]

46. Libby L, McEwan SR, Belch JJ, et al. Birth weight does not predict blood pressure in a young working population: a SHARP (Scottish Heart and Arterial Disease Risk Prevention) study. Ann Epidemiol. 2008; 18:298-301. [PubMed: 18083535]

47. Day, JC. Current Population Reports. Washington, D.C: U.S. Department of Commerce, Bureau of the Census; 1996. Population Projections of the United States, by Age, Sex, Race, and Hispanic Origin: 1995 to 2050.

48. Li C, Huang TTK, Cruz M, et al. Birth weight, puberty, and systolic blood pressure in children and adolescents: a longitudinal analysis. J Hum Hypertens. 2006; 20(6):444-50. [PubMed: 16617311]

49. Davies AA, Smith GD, May MT, et al. Association between birth weight and blood pressure is robust, amplifies with age, and may be underestimated. Hypertension. 2006; 48(3):431-6. [PubMed: 16880348]

50. Huxley R, Neil A, Collins R. Unravelling the fetal origins hypothesis: is there really an inverse association between birthweight and subsequent blood pressure? Lancet. 2002; 360(9334):659-65. [PubMed: 12241871]

51. Gillman MW. Epidemiological challenges in studying the fetal origins of adult chronic disease. Int J Epidemiol. 2002; 31(2):294-9. [PubMed: 11980782]

52. Eriksson J, Forsen T, Tuomilehto J, et al. Fetal and childhood growth and hypertension in adult life. Hypertension. 2000; 36(5):790-4. [PubMed: 11082144]

53. Law CM, Shiell AW, Newsome CA, et al. Fetal, infant, and childhood growth and adult blood pressure: a longitudinal study from birth to 22 years of age. Circulation. 2002; 105(9):1088-92. [PubMed: 11877360]

54. Li L, Law C, Power C. Body mass index throughout the life-course and blood pressure in midadult life: a birth cohort study. J Hypertens. 2007; 25(6):1215-23. [PubMed: 17563534]

55. Tzoulaki I, Sovio U, Pillas D, et al. Relation of immediate postnatal growth with obesity and related metabolic risk factors in adulthood: the Northern Finland Birth Cohort 1966 Study. Am J Epidemiol. 2010; 171(9):989-98. [PubMed: 20360243]

56. Cook S, Weitzman M, Auinger P, et al. Prevalence of a metabolic syndrome phenotype in adolescents: findings from the third National Health and Nutrition Examination Survey, 19881994. Arch Pediatr Adolesc Med. 2003; 157(8):821-7. [PubMed: 12912790]

57. Chen W, Srinivasan SR, Berenson GS. Amplification of the association between birthweight and blood pressure with age: the Bogalusa Heart Study. J Hypertens. 2010; 28(10):2046-52. [PubMed: 20616754]

58. Greenland P, Knoll MD, Stamler J, et al. Major risk factors as antecedents of fatal and nonfatal coronary heart disease events. JAMA. 2003; 290(7):891-7. [PubMed: 12928465]

59. Klag MJ, Ford DE, Mead LA, et al. Serum cholesterol in young men and subsequent cardiovascular disease. N Engl J Med. 1993; 328(5):313-8. [PubMed: 8419817]

60. Miura K, Daviglus ML, Dyer AR, et al. Relationship of blood pressure to 25-year mortality due to coronary heart disease, cardiovascular diseases, and all causes in young adult men - The Chicago Heart Association Detection Project in Industry. Arch Intern Med. 2001; 161(12):1501-8. [PubMed: 11427097]

61. Stamler J, Daviglus ML, Garside DB, et al. Relationship of baseline serum cholesterol levels in 3 large cohorts of younger men to long-term coronary, cardiovascular, and all-cause mortality and to longevity. JAMA. 2000; 284(3):311-8. [PubMed: 10891962] 


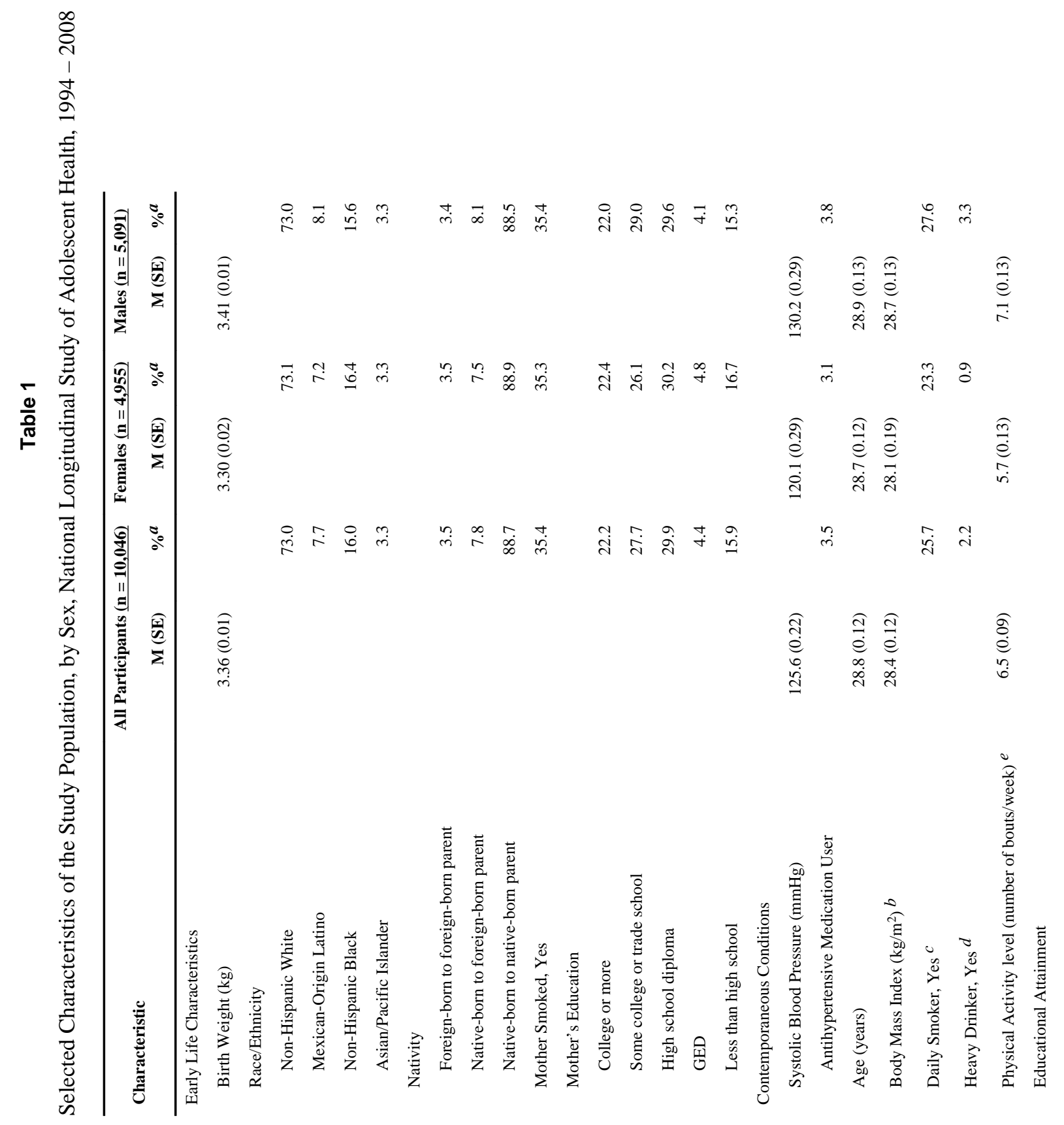




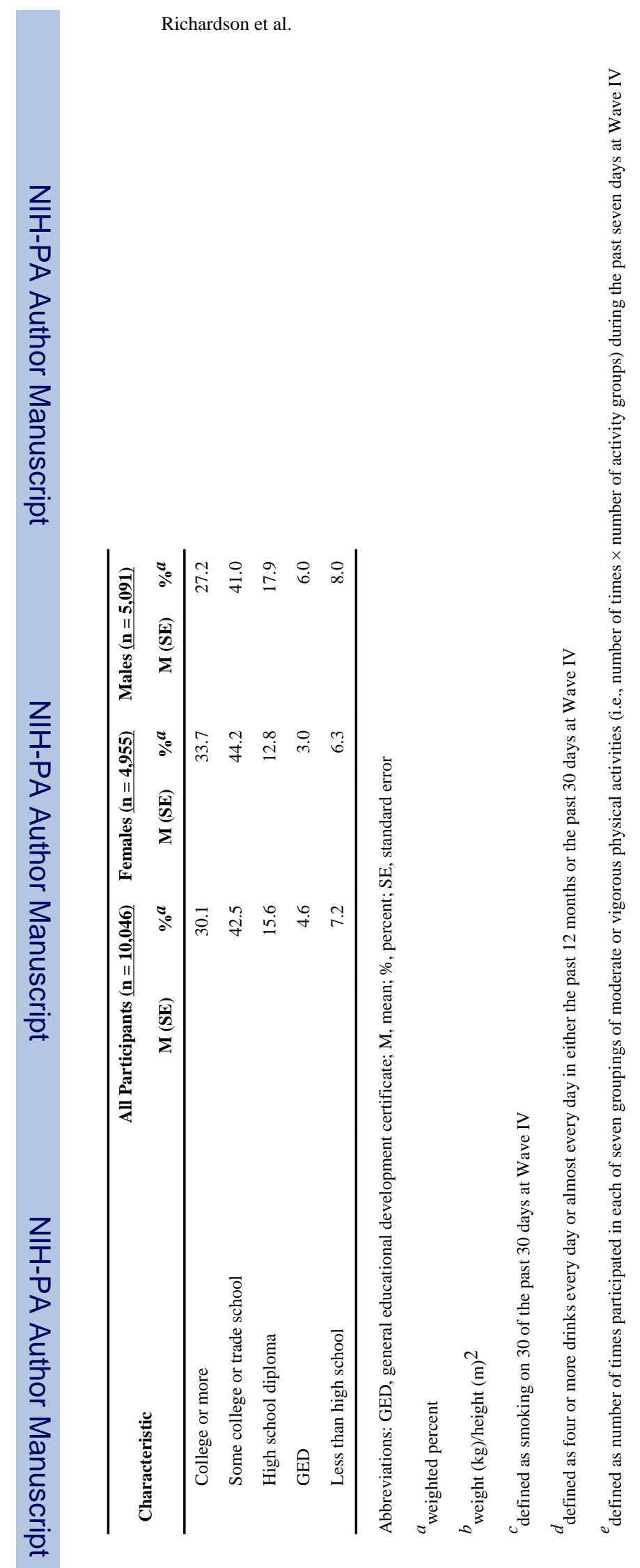

Ann Epidemiol. Author manuscript; available in PMC 2012 August 1. 


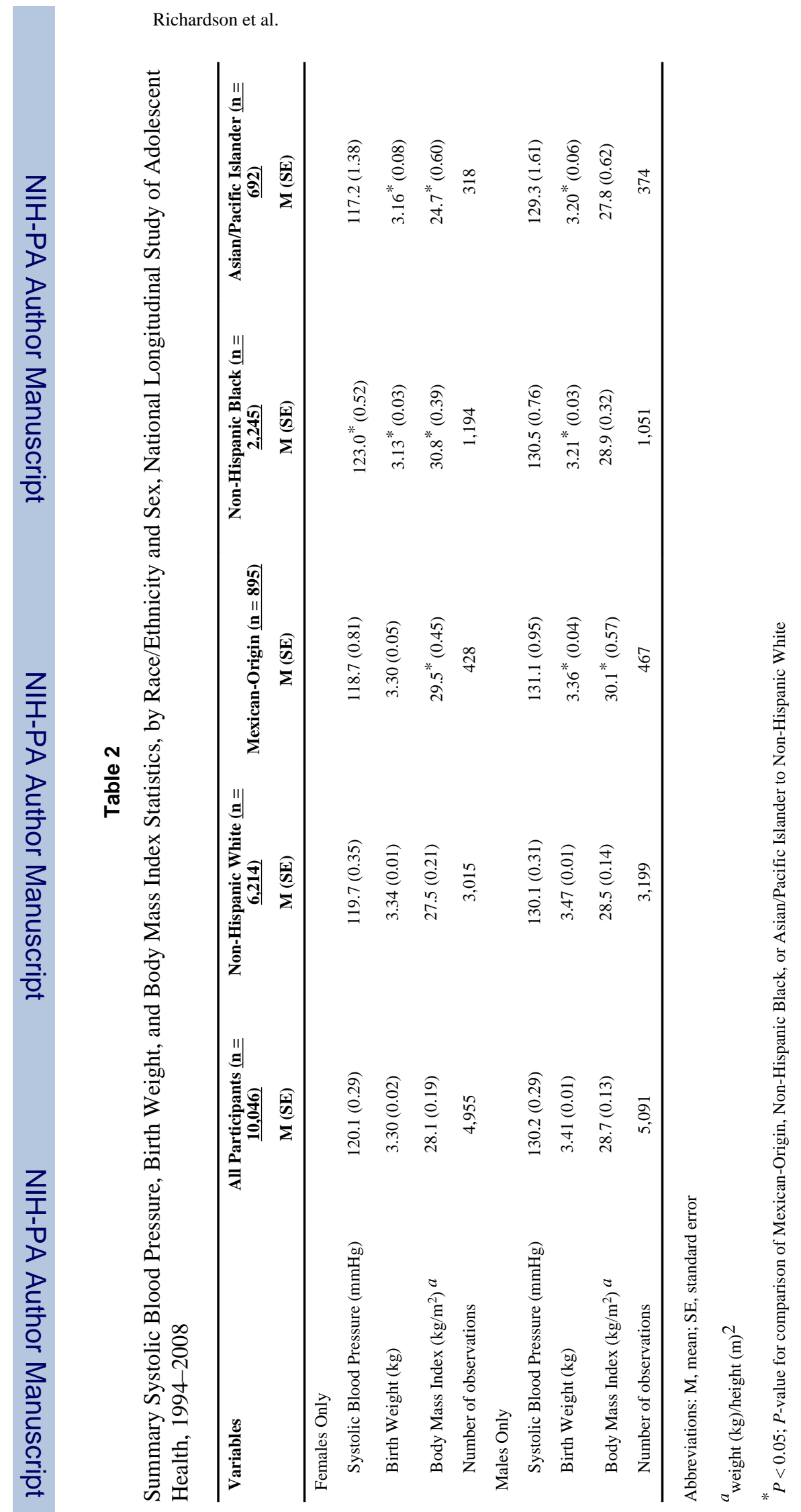

Ann Epidemiol. Author manuscript; available in PMC 2012 August 1. 


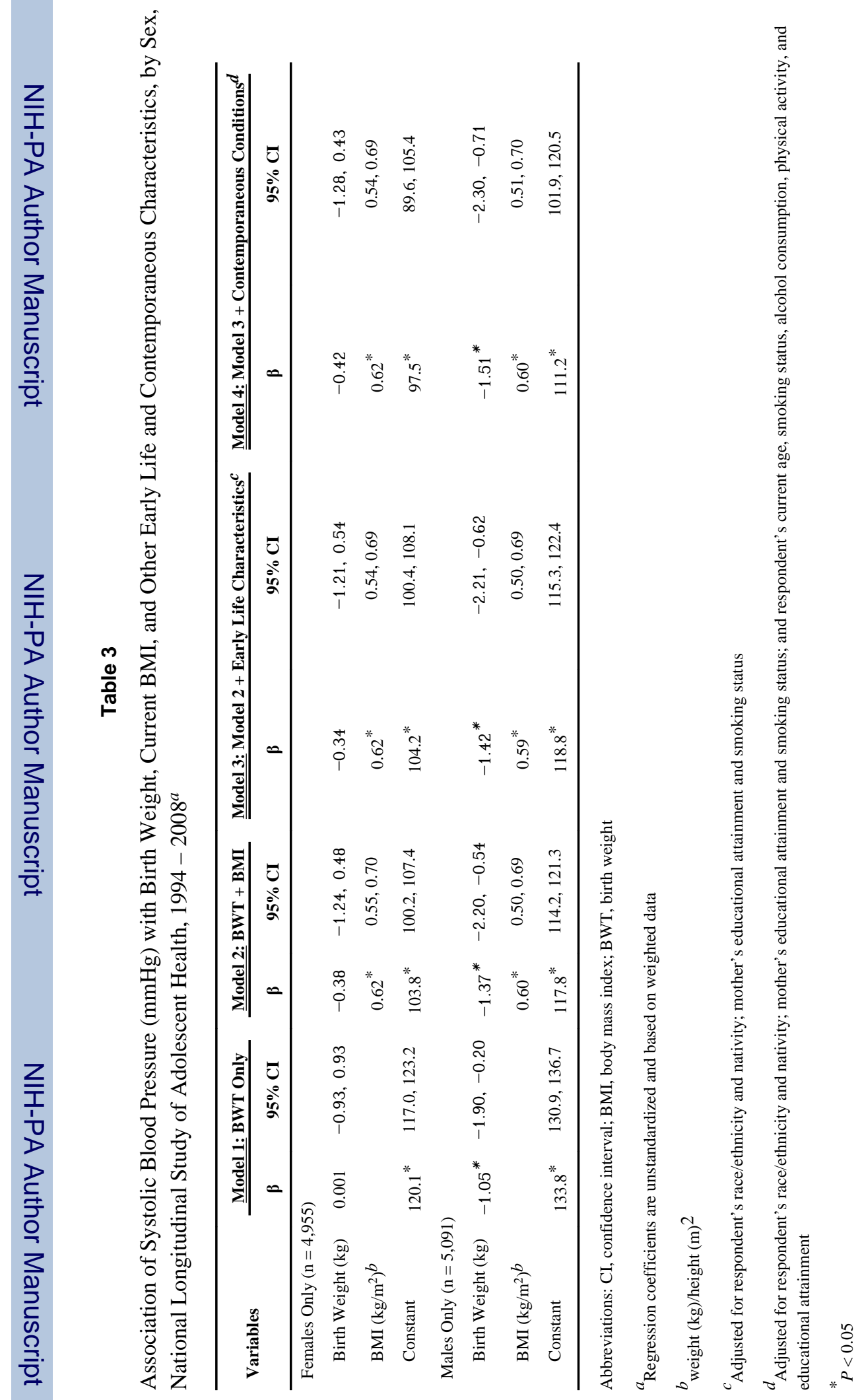




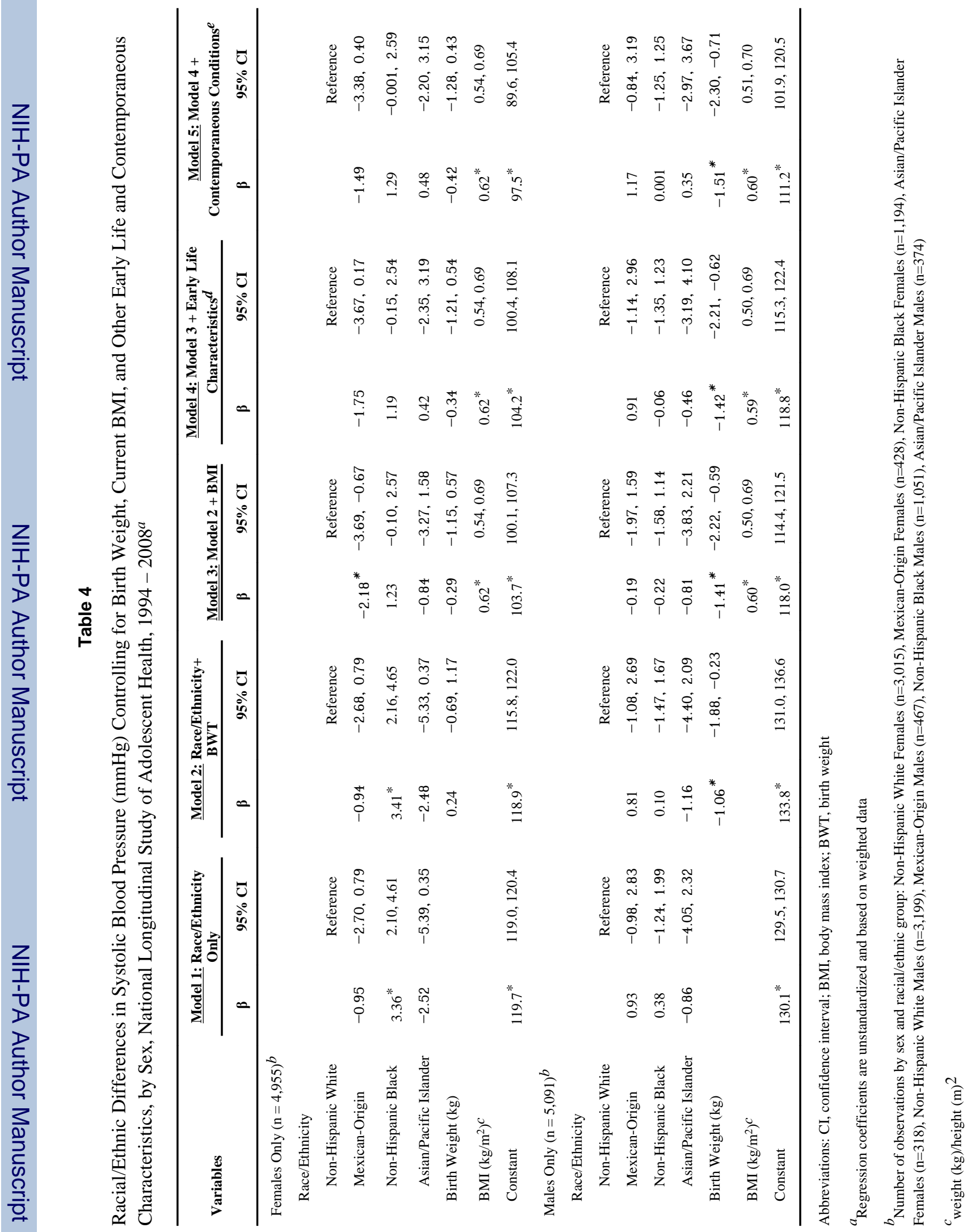




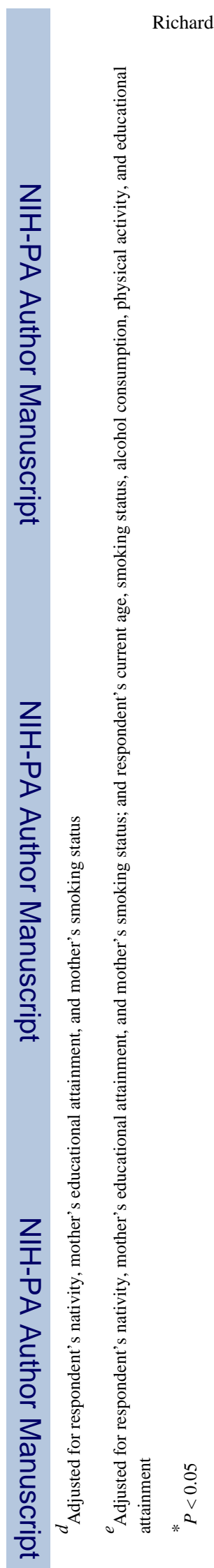

Ann Epidemiol. Author manuscript; available in PMC 2012 August 1. 


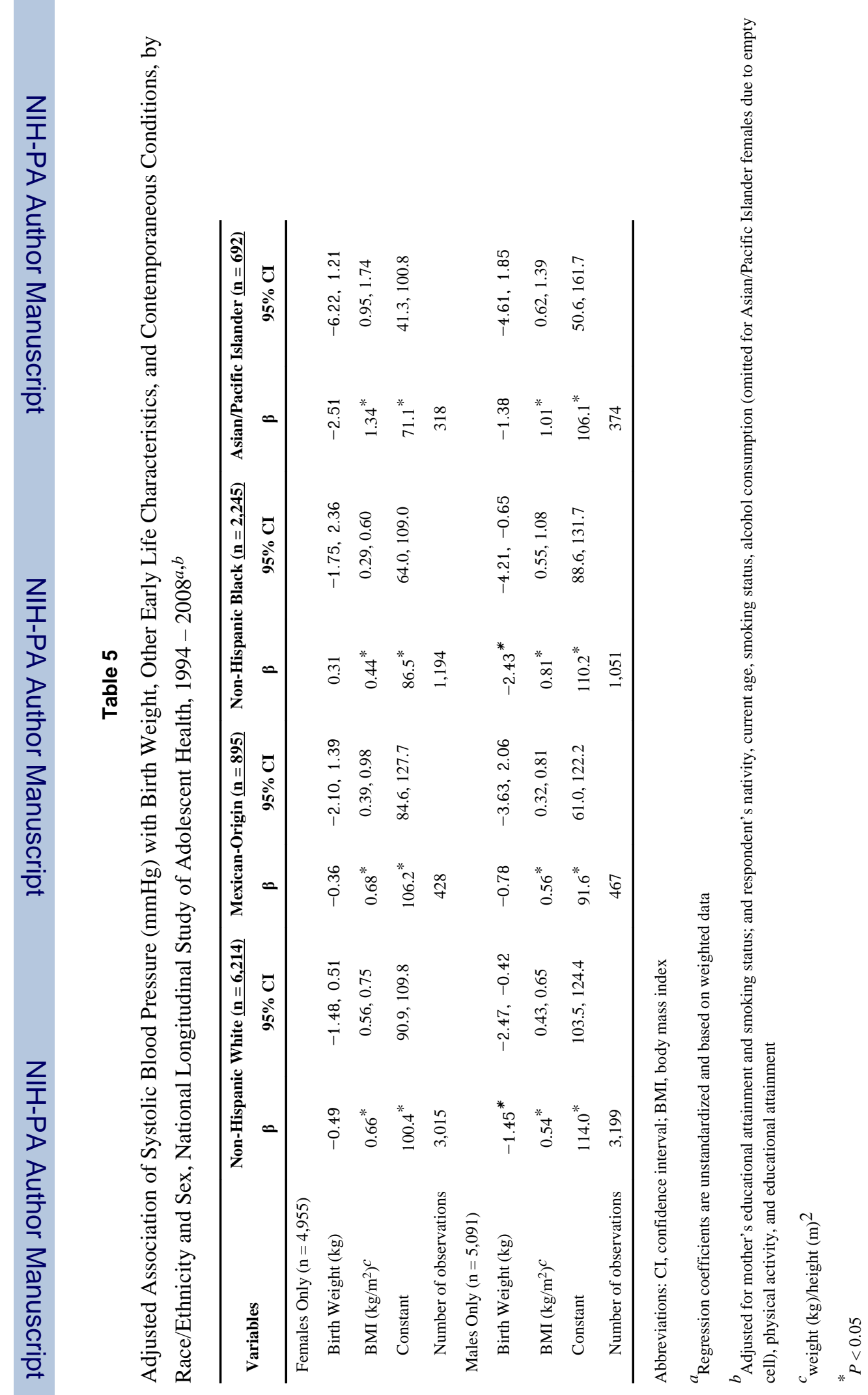

